\title{
PLASMAPHERESIS IN THE TREATMENT OF MYASTHENIA GRAVIS: OUTCOME AND COMPLICATIONS
}

\author{
Maryam Abbas, Helen Mary Robert, Asad Mahmood, Saleem Ahmed Khan, Mohammad Abdul Naeem, Muhammad Ahsan Ayaz \\ Armed Forces Institute of Pathology/National University of Medical Sciences (NUMS) Rawalpindi Pakistan
}

\begin{abstract}
Objective: To assess the outcome and complications of plasmapharesis in treatment of myasthenia gravis and factors linked to poor outcome at hematology unit of a tertiary care teaching hospital of Pakistan

Study Design: Prospective comparative study.

Place and Duration of Study: Pak Emirates Military Hospital/Armed Forces Institute of Pathology, Rawalpindi, from Jan 2018 to Jul 2019.

Methodology: A prospective study was conducted on patients of myasthenia gravis presented at our neurology department. All the complications of the procedure were recorded. Outcomes included recovery, shifting to intensive care unit and death. Pearson chi-square was applied to relate the factors with presence of complications or poor outcome.

Results: Hypotension $3(6 \%)$ was the commonest complication faced by the patients followed by chest discomfort $2(4 \%)$ during or after the plasmapharesis. Out of 50 patients, $47(94 \%)$ recovered, $8(16 \%)$ had minor complications, $2(4 \%)$ were shifted to the intensive care unit and $1(2 \%)$ died. Long duration of time between onset of symptoms and first session of plasmapharesis had a significant relationship $(p$-value $<0.05)$ with presence of complications or poor outcome among the patients of myasthenia gravis undergoing plasmapharesis.

Conclusion: Plasmapharesis emerged as effective treatment for this immune based neurological disorder with limited side effects. A neurologist should be aware of these common minor and rare major side effects and pay special attention to the patients with generalized myasthenia gravis and those with long duration of time between onset of symptoms and first session of plasmapharesis.
\end{abstract}

Keywords: Myasthenia Gravis, Outcome, Plasmapharesis.

This is an Open Access article distributed under the terms of the Creative Commons Attribution License (http://creativecommons.org/licenses/by/4.0), which permits unrestricted use, distribution, and reproduction in any medium, provided the original work is properly cited.

\section{INTRODUCTION}

Neuro-muscular disorders have been diagnosed frequently in the modern world after advent of newer diagnostic modalities ${ }^{1}$. Myasthenia gravis has been one of these disorders with fatigable muscle weakness and presence of different types of auto-antibodies in the serum of patients including acetylcholine receptors (AChRs), muscle-specific kinase (MuSK), or lipoprotein-related protein 4 (LPR4) ${ }^{2}$. Prevalence of this disorder has been on a rise in both developed and under developed countries ${ }^{3-5}$. This might be due to more cases getting diagnosed and treated in tertiary care facilities of all parts of the world.

Multiple management techniques have been in use for the treatment of this autoimmune neuromuscular disorder 6 . They have their own role in acute crisis as well as long term management of the illness. These modalities may be medical, surgical or sophisticated hematological procedures ${ }^{7}$. No treatment in medical science is free from side effects. Same is the case with treatment modalities of myasthenia gravis. Neurologist

Correspondence: Dr Maryam Abbas, Resident Haematology, Armed Forces Institute of Pathology, Rawalpindi Pakistan

Received: 19 Mar 2020; revised received: 03 Jun 2020; accepted: 17 Jun 2020 has to choose from steroids, immunomodulator drugs, plasmapharesis and thymectomy; the best option for the patient depending upon type of disease, condition of patient and overall weighing of risks and benefits ${ }^{8}$.

Despite multiple treatment options; plasmapharesis has usually been the treatment of choice in the acute phase of autoimmune disease like myasthenia gravis ${ }^{9}$. It is an effective mode of treatment in this condition but still has certain hazards associated with it. A study done in US concluded that procedure of plasmapharesis is safe and efficacious among the patients of myasthenia gravis but significant number of complications occur if there is delay in the start of management ${ }^{10}$. Another large review revealed that mortality associated with this procedure among myasthenia patients is around one percent and involve cardiac complications and non-cardiac pulmonary edema. A trial performed on pediatric population involving the comparison of plasmapharesis and intravenous immuneglobulins showed that plasmapharesis emerged as a more effective mode of treatment with limited number of benign and self-limiting complications. Mild side effects like reversible hypotension and paraesthesias were reported in study done on patients of myasthenia undergo- 
ing plasmapharesis at a university hospital. Zero mortality was reported due to this procedure.

Neurology has been an evolving specialty in our country along with immunology with a limited number of trained physicians. Moreover liaison between different specialties has also been lacking during the overall management of a patient with a complex disorder. Usually clinicians prescribe the treatment and technicians or immune-therapist or hematologist perform it. Clinicians are only involved when some serious side effect occurs or the patient has to be shifted to intensive care unit. We therefore planned this study with the rationale to assess the outcome and complications of plasmapharesis in treatment of myasthenia gravis and factors linked to poor outcome among the patients referred from various neurological centers of the twin cities of Rawalpindi and Islamabad.

\section{METHODOLOGY}

This prospective comparative study was conducted at Neurology department, Pak Emirates Military Hospital (PEMH) Rawalpindi, from Jan 2018 to Jul 2019. Sample was gathered by using the non-probability consecutive sampling technique. Sample size was calculated by using the WHO sample size calculator by using population prevalence proportion of $1.15 \%^{10}$. All patients between the age of 12-65 years suffering from generalized myasthenia gravis and referred to Neurology department PEMH Rawalpindi for plasmapheresis were included in the study. Patients who were referred from military, public sector and private hospitals with the same diagnosis were included in the analysis in addition to the referrals from the other wards of own hospital. Diagnosis of myasthenia gravis was made by incorporating the clinical findings and diagnostic modalities on the basis of following ${ }^{11-13}$.

Fluctuating muscle weakness and one or more of the following results: (1) positive response to Pyridostigmine; (2) more than $10 \%$ decreased amplitude of the compound muscle action potential in the repetitive nerve stimulation; (3) increased jitter on single-fiber electromyography (SFEMG); (4) positive AChR antibody assay. A criterion set by Myasthenia Gravis Foundation of America was used to classify the patients according to the severity of illness ${ }^{14-16}$.

Exclusion criteria were the patients with less than 12 years of age or those with unclear medical diagnosis or those with ocular myasthenia gravis. Pregnant patients or those with other ocular or neuromuscular comorbidities were also not included in the study. Any major organ failure like lungs, liver or kidney was also part of exclusion criteria. Patients with diabetes, neoplasia, hypothyroidism, vasculitis, or history of intoxication or those who did not give written informed consent were also excluded from the study.

Ethics approval was taken from the ethical review board committee for this study via IREB letter no. 25. After written informed consent from the potential participants, patients with myasthenia gravis in the Pak Emirates Military Hospital Rawalpindi fulfilling the above mentioned criteria of inclusion and exclusion were included in the study. Parents of patients were asked for consent who were less than 18 years of age and they were only include if both the patient and parents gave informed consent. Proper clinical and laboratory investigations like ECG, chest X-ray, cardiorespiratory status and serology were carried out before this procedure. Anticoagulation with citrate was systematically used. Replacement of plasma removed during the session was performed with isotonic sterile saline, to make up one-half of the volume and with $5 \%$ purified human albumin and fresh frozen plasma to complete it. A careful monitoring of hemodynamic parameters was done, and complications during or following TPE were rapidly recognized and reverted by rationale interventions of the medical staff that assisted the procedure.

Calcium replacement with $10 \mathrm{ml}$ of $10 \%$ Calcium Gluconate was infused over $15 \mathrm{~min}$ approximately halfway through the procedure to avoid citrate toxicity ${ }^{17}$. Patients were observed and asked for the adverse effects during the procedure and till 48 hours after the procedure. Outcome was classed as patients returned to ward without any major event due to this procedure or shifted to ICU or died during or soon after the procedure due to any lethal complication of the procedure but not due to underlying illness or any other cause.

All statistical analysis was performed by using the Statistics Package for Social Sciences version 24.0 (SPSS-23). Mean and standard deviation for the age of study participants was calculated. Frequency and percentages for gender and complications of plasmapharesis and outcome was calculated. Pearson chi-square analysis was used to establish relationship between socio-demographic factors and presence of poor outcome or complications among the study participants.

\section{RESULTS}

A total of 53 patients were referred to neurology unit PEMH for plasmapharesis with diagnosis of myasthenia gravis were initially approached to get them included in the analysis. One had no clear diagnosis of 
the underlying medical condition, one was pregnant and one patient did not give consent to get include him in the study. Out of 50 patients included in the final analysis $30(60 \%)$ were male and $20(40 \%)$ were female. Mean age of patients diagnosed with myasthenia gravis in our study was $30.27 \pm 4.381$ years. Other characteristics of study population have been summarized in table-I. Hypotension $3(6 \%)$ was the commonest complication faced by the patients followed by chest discomfort 2 (4\%) (table-I). Out of 50 patients, 47 (94\%) recovered, $8(16 \%)$ had minor complications, $2(4 \%)$ were shifted to the intensive care unit and $1(2 \%)$ died (tableII). Pearson chi-square analysis showed that long duration of time between onset of symptoms and first session of plasmapharesis had significant relationship with presence of complications or poor outcome among the patients of myasthenia gravis undergoing plasmapharesis in our study (table-III).

Table-I: Characteristics of patients admitted with myasthenia gravis $(n=50)$.

\begin{tabular}{l|c}
\hline \multicolumn{2}{l}{ Age (years) } \\
\hline $\begin{array}{l}\text { Mean } \pm \text { SD } \\
\text { Range (min-max) }\end{array}$ & $\begin{array}{c}30.27 \pm 4.381 \\
12-56 \text { years }\end{array}$ \\
\hline Gender & $30(60 \%)$ \\
\hline Male & $20(40 \%)$ \\
Female & $01(2 \%)$ \\
\hline Complications of Plasmapharesis \\
\hline Allergic reaction & $01(2 \%)$ \\
Abdominal pain & $02(4 \%)$ \\
Chest discomfort & $01(2 \%)$ \\
Fever & $03(6 \%)$ \\
Hypotension &
\end{tabular}

Table-II: Outcome of patients diagnosed as myasthenia gravis and treated with Plasmapheresis.

\begin{tabular}{l|c|c|c|c}
\hline Total & Recovery & $\begin{array}{c}\text { Minor } \\
\text { Complications }\end{array}$ & $\begin{array}{c}\text { Shifted } \\
\text { to ICU }\end{array}$ & Death \\
\hline 50 & $47(94 \%)$ & $8(16 \%)$ & $2(4 \%)$ & $1(2 \%)$ \\
\hline
\end{tabular}

Table-III: Relationship of factors with outcome of plasmapheresis.

\begin{tabular}{l|c|c|c}
$\begin{array}{l}\text { Socio- } \\
\text { Demographic } \\
\text { Factors }\end{array}$ & $\begin{array}{c}\text { No } \\
\text { Complication } \\
\text { or Good } \\
\text { Outcome }\end{array}$ & $\begin{array}{c}\text { Presence of } \\
\text { Complication } \\
\text { or Poor } \\
\text { Outcome }\end{array}$ & $\begin{array}{c}p \text { - } \\
\text { value }\end{array}$ \\
\hline Age & $\begin{array}{l}(48.7 \%) \\
(51.3 \%)\end{array}$ & $02(18.1 \%)$ & $09(81.9 \%)$ \\
\hline $\begin{array}{l}12-18 \text { year } \\
>18\end{array}$ & $22(56.4 \%)$ & $08(72.7 \%)$ & 0.059 \\
\hline Gender & $17(43.6 \%)$ & $03(27.3 \%)$ & 0.320 \\
\hline Male & $\begin{array}{l}\text { Female } \\
\text { Time to Plasmapheresis After Onset of Symptoms }\end{array}$ \\
\hline$<1$ week & $37(94.8 \%)$ & $02(18.1 \%)$ & $<0.001$ \\
$>1$ week & $02(5.2 \%)$ & $09(81.9 \%)$ & $<$
\end{tabular}

\section{DISCUSSION}

Autoimmune disorders make a big chunk of disorders presenting to almost all the specialty clinics including Neurology, Rheumatology, Nephrology, Hematology, Gynecology, Endocrinology and Gastroenterology. A good liaison among these specialties and immunologist serves as a key for effective treatment of these patients suffering from problems involving multiple systems and making their life miserable ${ }^{14}$. Neurology also involves a lot of immune based disorders and doctors working in this specialty need an adequate knowledge of immunology in order to timely diagnose and treat these disorders ${ }^{16-18}$. Myasthenia gravis is one of the fairly common autoimmune neurological disorders which can present in number of ways and can be life threatening if not managed well in time ${ }^{4,19}$. This study therefore was planned with the rationale to assess the outcome and complications of plasmapharesis in treatment of myasthenia gravis and factors linked to poor outcome at hematology unit of a tertiary care teaching hospital of Pakistan.

A large review revealed that mortality associated with this procedure among myasthenia patients is around one percent and involve cardiac complications and non-cardiac pulmonary edema ${ }^{11}$. A trial performed on pediatric population involving the comparison of plasmapharesis and intravenous immune-globulins showed that plasmapharesis emerged as a more effective mode of treatment with limited number of benign and self-limiting complications ${ }^{12}$. Mild side effects like reversible hypotension and paraesthesias were reported in study done on patients of myasthenia undergoing plasmapharesis at a university hospital. Zero mortality was reported due to this procedure ${ }^{13}$.

Neurology has been an evolving specialty in our country along with immunology with a limited number of trained physicians ${ }^{14}$.

Plasmapharesis has now been considered as a time tested and effective mode of treatment for many immunological disorders especially in the west where it had been in practice for decades now. Mantegazza et al in 2018 published a comprehensive paper int his regard labelling plasmapheresis as one of the best treatment options for MG9. It has played a great role in minimizing the mortality and morbidity due to the complex immune based diseases. It has been in use to manage the myasthenia gravis for quite a long time with good results and minimum side effects. Study of Behin et al published in 2018 highlighting all the major options for patients of MG is important in this regard ${ }^{8}$. 
Results in our study were also in accordance with the results of studies done by Liew et al in 2014 and Carandina-Maffeis et al in 2004 in the west on the patients of myasthenia gravis ${ }^{12,13}$. Most of our patients (94\%) had a good recovery and were discharged from the respective neurology wards after the adequate treatment. Two patients needed the mechanical ventilation and shift in the critical care unit which highlights the importance of managing such case at a tertiary care hospital with lifesaving facilities. Only one patient died within 48 hours of the procedure. The patients which had poor outcome i.e. death or shift to CCU could also be accounted to the disease itself instead of treatment but as they occurred after the procedure so were enrolled in the study.

Long duration of time between onset of symptoms and first session of plasmapharesisi-e those who were treated after one week of the start of symptoms had more chances of developing complications as compared to those who started treatment early. It has been reported in the past as well in the study done by Mandawat et al in 2011 where long duration of untreated illness had significant relationship ( $p$-value $<0.05$ ) with presence of the complications ${ }^{10}$. Long duration of untreated illness may be associated with more damage with autoantibodies and may be responsible for untoward outcome after the plasmapharesis.

Shemin et al20 in a study in 2007 concluded that most complications were minor; there were no deaths. Three treatments $(0.2 \%)$ were discontinued due to a complication, and $2(0.1 \%)$ required transfer to a higher acuity hospital bed. The most common complications were fever $(7.7 \%$ of treatments), urticaria $(7.4 \%)$, and hypocalcemic symptoms $(7.3 \%), 42 \%$ of treatments with FFP involved a complication, compared to $30 \%$ of treatments using albumin-saline $(p<0.0001)$. The most common complications with FFP were urticaria (17\%) and pruritus $(13 \%)$; these occurred more commonly than in patients receiving albumin-saline. The most common complications with albumin-saline replacement were hypocalcemic symptoms $(8.2 \%)$ and mild hypotension $(8.1 \%)$. Mild and severe hypotension was significantly $(p<0.0001)$ more common with albuminsaline replacement ${ }^{20}$. Our results were a bit different and we concluded that Hypotension $3(6 \%)$ was the commonest complication faced by the patients followed by chest discomfort $2(4 \%)$ during or after the plasmapharesis. Out of 50 patients, $47(94 \%)$ recovered, 08 $(16 \%)$ had minor complications, $02(4 \%)$ were shifted to the intensive care unit and $01(2 \%)$ died.
The study design we opted for this stud pose a major limitation and results could not be generalized. Comparison between two treatment options or a randomized control trial would have generated better results. Sample was from a single military hospital therefore even results with this design could not be regarded as representative of the whole population. Enrolling the patients from public and private settings and comparing various treatment modalities may guide the clinicians to formulate some local guidelines in this regard.

\section{CONCLUSION}

Plasmapharesis emerged as effective treatment for this immune based neurological disorder with limited side effects. A neurologist should be aware of these common minor and rare major side effects and pay special attention to the patients with generalized myasthenia gravis and those with long duration of time between onset of symptoms and first session of plasmapharesis.

\section{CONFLICT OF INTEREST}

This study has no conflict of interest to be declared by any author.

\section{REFERENCES}

1. Roy AJ, Van den Bergh P, Van Damme P, Doggen K, Van Casteren V, et al. Early stages of building a rare disease registry, methods and 2010 data from the Belgian Neuromuscular Disease Registry (BNMDR). Acta Neurol Belg 2014; 115(2): 97-104.

2. Sanders DB, Wolfe GI, Benatar M,Evoli A, Gilhus NE, Illa I, et al. International consensus guidance for management of myasthenia gravis: Executive summary. Neurology 2016; 87(4): 419-25.

3. Lin CW, Chen TC, Jou JR, Woung LC. Update on ocular myasthenia gravis in Taiwan. Taiwan J Ophthalmol 2018; 8(2): 67-73.

4. Tanovska N, Novotni G, Sazdova-Burneska S, Kuzmanovskil, Boshkovski B, Kondovet G, et al. Myasthenia Gravis and Associated Diseases. Open Access Maced J Med Sci 2018; 6(3): 472-78.

5. Lai CH, Tseng HF. Nationwide population-based epidemiological study of myasthenia gravis in taiwan. Neuroepidemiol 2010; 35(1): 66-71.

6. Jordan A, Freimer M. Recent advances in understanding and managing myasthenia gravis. F1000Res 2018; 7 (1): F1000.

7. Cataneo AJM, Felisberto G, Cataneo DC. Thymectomy in nonthymomatous myasthenia gravis - systematic review and metaanalysis. Orphanet J Rare Dis 2018; 13(1): 99.

8. Behin A, Le Panse R. New pathways and therapeutic targets in autoimmune myasthenia gravis. J Neuromuscul Dis 2018; 5(3): 265-77.

9. Mantegazza R, Antozzi C. When myasthenia gravis is deemed refractory: clinical signposts and treatment strategies. Ther Adv Neurol Disord 2018; 21(11): 1756286418765591.

10. Mandawat A, Mandawat A, Kaminski HJ, Shaker ZA, Alawi AA. Outcome of plasmapheresis in myasthenia gravis: delayed therapy is not favorable. Muscle Nerve 2011; 43(4): 578-84.

11. Ussel A, Sitthy X, Reviron J. Technical aspects and complications of plasmaexchange. La Ricerca Clin Lab 1983; 13(1): 111. 
12. Liew WK, Powell CA, Sloan SR, Shamberger RC, Weldon CB, Darras BT, et al. Comparison of plasmapheresis and intravenous immunoglobulin as maintenance therapies for juvenile myasthenia gravis. J Am Med Assoc Neurol 2014; 71(5): 575-80.

13. Carandina-Maffeis R, Nucci A, Marques JF, Roveri EG, Pfeilsticker BH, Garibaldi SG, et al. Plasmapheresis in the treatment of myasthenia gravis: retrospective study of 26 patients. Arq Neuropsiquiatr 2004; 62(2B): 391-95.

14. Saeed M, Ahmad A. Neuroimmunology: An expanding frontier in 21st century Neurology. Pak J Neurol Sci 2017; 12 (3): 1-2.

15. Juel VC, Massey JM. Myasthenia gravis. Orphanet J Rare Dis 2007; 2(3): 44

16. Phillips WD. Pathogenesis of myasthenia gravis: up-date on disease types, models, and mechanisms. F1000Res 2016; 5: F1000.

17. Bobati SS, Naik KR. Therapeutic plasma exchange - an emerging treatment modality in patients with neurologic and non-neurologic diseases. J Clin Diagn Res 2017; 11(8): EC35-EC37.

18. Piquet AL, Clardy SL. Infection, Immunodeficiency, and inflammatory diseases in autoimmune neurology. Semin Neurol 2018; 38(3): 379-91.

19. Roh HS, Lee SY, Yoon JS. Comparison of clinical manifestations between patients with ocular myasthenia gravis and generalized myasthenia gravis. Korean J Ophthalmol 2011; 25(1): 1-7.

20. Shemin D, Briggs D, Greenan M. Complications of therapeutic plasma exchange: a prospective study of 1,727 procedures. J Clin Apher 2007; 22(5): 270-76. 